\title{
O problema da co-especialização no desenvolvimento colaborativo de novos produtos
}

\author{
António Carrizo Moreira \\ Professor Auxiliar da Universidade de Aveiro
}

\begin{abstract}
Resumo
As abordagens cooperativas têm substituído algumas abordagens antagonistas na cadeia de valor, dando origem a relacionamentos inter-empresariais colaborativos. Um dos grandes desafios destas abordagens cooperativas tem sido o desenvolvimento de novos produtos envolvendo empresas industriais ao longo da cadeia de valor, especialmente os fornecedores e os seus clientes (produtores), devido fundamentalmente à complexidade do produto e à evolução dos interesses estratégicos das empresas intervenientes.

A natureza destas colaborações varia conforme o tipo de indústria, o tipo de parceiros e o tipo de inovação introduzida. Embora alguns modelos tenham sido desenvolvidos com o intuito de explicar a progressiva integração dos fornecedores no negócio-chave do produtor, o artigo pretende abordar as diferentes teorias da inovação, relacioná-las com a mudança tecnológica no contexto específico da mudança partilhada entre empresas ao longo da cadeia de valor, de forma a mostrar, por intermédio do conceito de co-especialização, que há situações desvantajosas para o fornecedor que tornam potencialmente inviáveis algumas abordagens cooperativas.

Metodologicamente foi seguida uma abordagem teórica para expor tanto os conceitos como as conclusões. No final do artigo são apresentadas algumas recomendações que apontam no sentido do aprofundamento dos relacionamentos colaborativos, sobretudo, em duas situações completamente diferentes e que se relacionam com a coespecialização dos parceiros e com o tipo de produto transacionado entre ambos.
\end{abstract}

Palavras-chave

Estratégias de inovação, estratégias tecnológicas, desenvolvimento colaborativo.

\section{The co-specialization problem in collaborative new product development}

\begin{abstract}
Cooperative approaches have been replacing antagonistic ones along the value chain. Collaborative product development has been one of the major challenges in cooperative strategies, namely in the supplier-producer relationship, due to product complexity and evolving strategic interests of both intervening firms.

The nature of collaborations varies according to industry, to types of partners and to type of product innovation. Some models have been developed in order to explain the progressive integration of the suppliers into the producer's business. Nevertheless, the purpose of this paper is to approach the different innovation theories and to use the concept of co-specialization in order to show that there are some disadvantageous situations for suppliers not covered by general models.

Methodologically a theoretical approach was followed in order to explain the concepts as well as the conclusions. In the end of the paper, some recommendations are put forward in order to deepen the collaborative relationships especially the situations in which the type of product transactioned and the co-specialization differ.
\end{abstract}

Key words

Innovation strategies, technological strategies, collaborative new product development. 


\section{INTRODUĈ̣̃O}

Desde há muito que a procura e o desenvolvimento de vantagens competitivas têm norteado as estratégias empresariais. A tecnologia e a inovação têm sido meios importantes na geração dessas vantagens competitivas (PORTER, 1985; ORTEGA, 1991).

A tecnologia influencia a estratégia pelo seu caráter muitas vezes tácito e cumulativo ao longo do tempo (PAVITT, 1985). Assim, a atitude da empresa deve ser aberta, tendo como referência a dinâmica industrial a nível de novas tecnologias, de novos processos produtivos e de desenvolvimento de novos produtos. Como conseqüência, o importante não é o domínio específico de uma tecnologia mas antes a capacidade da empresa em dominar convenientemente as suas aplicações. A inovação, por seu lado, como fonte de sucesso e de vantagem competitiva deve responder a uma obrigação fundamental da empresa: o domínio das aplicações tecnológicas (RIBAULT et al., 1995). Desta forma, o processo de inovação se assume como o veículo de competitividade da empresa e o domínio das aplicações tecnológicas como a sua vantagem competitiva.
A literatura sobre o DNP tem tratado a tecnologia e a inovação como tendo origem no seio da empresa, sendo internalizáveis as vantagens competitivas delas resultantes. Só recentemente Rothwell (1994) pôs em causa essa visão. O advento das abordagens colaborativas trouxe consigo uma nova atitude relacional que obrigou ao abandono de abordagens antagônicas ao longo da cadeia de valor e ao envolvimento dos fornecedores no processo de desenvolvimento colaborativo de novos produtos.

Kamath e Liker (1994) deram uma contribuição importante ao relacionamento inter-empresarial ao abordálo do ponto de vista do fornecedor e não do cliente, como classicamente acontecia. No entanto, quando se consideram os diferentes tipos de produtos (componentes, subprodutos e sistemas) e a sua complexidade tecnológica, o relacionamento pode não ser tão linear como Kamath et al. (1994) propõem. Assim, tendo em consideração (a) o interesse dos fornecedores e dos clientes; (b) o tipo de produto e a sua trajetória tecnológica; e (c) o grau de co-especialização dos parceiros no desenvolvimento colaborativo de novos produtos, o artigo aborda duas situações que não são mencionadas na literatura técnica sobre a inovação tecnológica e sobre o desenvolvimento de novos produtos.

$\mathrm{O}$ artigo tem como principal finalidade mostrar, por intermédio do conceito de co-especialização, que há situações

A importância da inovação se tem feito sentir como motor de desenvolvimento e de exploração das oportunidades surgidas. A inovação tecnológica tem sido um desafio constante no processo de desenvolvimento de novos produtos (ABERNATHY e UTTERBACK, 1975), nomeadamente na gestão do design dominante, o que influencia a gestão da inovação.

As descontinuidades tecnológicas têm feito sentir a sua influência no processo de desenvolvimento de novos produtos (DNP), sobretudo, porque algumas competências nucleares das empresas são destruídas e outras emergem, forçando as empresas a fazer uma adequada gestão das suas competências e do processo de mudança (ANDERSON et al., 1990).

O desenvolvimento de novos produtos está associado ao bom desempenho empresarial. Urban e Hauser (1993) identificaram vários fatores que são importantes, quando do lançamento de novos produtos, como por exemplo os relacionados com o mercado, com a geração de idéias, com a gestão dos recursos e com a gestão da inovação tecnológica. desvantajosas para o fornecedor que tornam potencialmente inviáveis algumas abordagens cooperativas, contribuindo, assim, para a discussão das teorias dos relacionamentos cooperativos. Começa-se por abordar a inovação e a temática do DNP, onde são identificados os fatores de sucesso e insucesso no lançamento de novos produtos, e os fatores de sucesso no desempenho empresarial. Seguidamente, é abordado o envolvimento dos fornecedores no processo de desenvolvimento colaborativo de novos produtos, por um lado, e a problemática da evolução do relacionamento inter-empresarial, por outro. Posteriormente, é apresentada uma retrospectiva crítica onde se aglomeram as diversas teorias sobre a tecnologia, a inovação, o DNP e o relacionamento inter-empresarial. O artigo explora, igualmente, a necessidade de abordar o tema da co-especialização entre as empresas fornecedoras e produtoras, de forma a explicar comportamentos não colaborativos quando a trajetória tecnológica e o design dominante já foram atingidos. Finalmente, são apresentadas as principais conclusões. 


\section{A INOVAC̣̃̃O E O DESENVOLVIMENTO DOS NOVOS PRODUTOS}

A globalização e a crescente competitividade internacional têm influenciado o DNP. De acordo com Griffin (1997), enquanto que $49 \%$ do crescimento das empresas bem-sucedidas era devido ao adequado lançamento de novos produtos, estes eram apenas responsáveis por $24 \%$ do crescimento das vendas das empresas menos sucedidas. Estes resultados deram crédito às teses de Urban e Hauser (1993), que defendiam que a importância do desempenho empresarial era devida ao contínuo DNP e à adequada gestão das suas características.

Dado que a inovação pode ser entendida como a criação de algo diferente, de forma a encarar novos desafios, ela representa um desafio constante na criação de novos produtos e na gestão dos principais intervenientes no processo de desenvolvimento colaborativo.

De acordo com Deschamps e Nayak (1995), identificar as necessidades dos clientes e gerar novas idéias que originem produtos inovadores é um dos principais imperativos estratégicos das empresas.

Aquando do desenvolvimento de novos produtos, há aspectos a ter em conta que influenciam a sua aceitação no mercado. Os mais importantes estão relacionados com a adequada identificação das necessidades dos consumidores, o grau de satisfação dos clientes, o grau de inovação dos produtos e o desempenho de marketing da empresa. Urban e Hauser (1993) vão mais longe ao identificar os fatores de sucesso e os motivos de insucesso no DNP. Conforme se apresenta na Tabela 1, os dois estão relacionados com a estratégia e com a gestão dos processos organizacionais e comunicacionais, pelo que é possível concluir que uma adequada atenção às fraquezas organizacionais no processo de DNP é de crucial importância na gestão colaborativa de novos produtos.

$\mathrm{O}$ estudo dos fatores-chave de sucesso que levam ao adequado desenvolvimento de novos produtos tem sido um tema controverso. Ernst (2002) pôs em causa alguns dos resultados obtidos pelos gurus do DNP, sobretudo por questões metodológicas. Tendo como unidade de avaliação a empresa e não o produto, Ernst (2002), tal como apresentado na Tabela 2 , defende que há cinco fatores de sucesso capazes de influenciar o desempenho empresarial, a saber: a) o processo de desenvolvimento de novos produtos; b) a organização desse processo; c) a cultura empresarial; d) o compromisso e a atuação da gestão do topo; e e) a estratégia de DNP.

É possível se afirmar que, tanto a nível de empresa como a nível de projeto, ambas abordagens levam a

Tabela 1: Fatores de sucesso e de insucesso no lançamento de novos produtos.

\begin{tabular}{|c|c|}
\hline FATORES DE SUCESSO & MOTIVOS DE INSUGESSO \\
\hline Responsivas às necessidades dos consumidores & Mercado reduzido \\
\hline Elevado valor acrescentado para os clientes & Falhas de previsão \\
\hline Produtos inovadores & Produtos pouco inovadores \\
\hline Superioridade técnica & Fraco retorno do investimento \\
\hline Sistema de apoio à decisão e análise & Problemas organizacionais \\
\hline Ambiente competitivo favorável & Falhas na coordenação inter-funcional \\
\hline Adequação da organização à indústria & Mudanças nos gostos dos consumidores \\
\hline Comunicação inter-funcional & Fraco posicionamento estratégico \\
\hline Compromisso da gestão de topo & Inadequado tratamento do canal distribuidor \\
\hline Processo disciplinado de desenvolvimento de novos & Mutações tecnológicas quando do desenvolvimento \\
\hline produtos & Processo disciplinado de desenvolvimento de novos \\
\hline Departamento dinâmico de desenvolvimento & produtos \\
\hline Time-to-market reduzido & Mudanças no ambiente competitivo \\
\hline Aversão a riscos desnecessários & Fraco serviço pós-venda \\
\hline \multicolumn{2}{|l|}{ Estratégia global } \\
\hline $\begin{array}{l}\text { Orientação para a qualidade e para a satisfação do } \\
\text { consumidor }\end{array}$ & \\
\hline
\end{tabular}

Fonte: Urban e Hauser (1993). 
conclusões relativamente semelhantes. A grande diferença entre elas está na unidade avaliada: a consideração do desempenho pode levar a conclusões diferentes quando a unidade avaliada é o produto ou a empresa, dado que nem todos os novos produtos são igualmente importantes para as empresas. Como se depreende das Tabelas 1 e 2, o DNP é um elemento que requer uma gestão cuidadosa tanto a nível estratégico como a nível operacional, pelo que um dos grandes desafios da inovação está ligado à capacidade das empresas em responder às mudanças tecnológicas e às mutações do mercado.

O lançamento de novos produtos no mercado é um processo que envolve algum risco, dado que está associado a mudanças tecnológicas, bem como a alterações do mercado que implicam modificações na composição da oferta da empresa.

A criação de novos produtos pode ser vista tal como Schumpeter (1943) entendeu a inovação: como um processo de destruição criativo, i.e., como motor de desen-

\section{Tabela 2: Fatores de sucesso no desempenho} empresarial.

Processo de Desenvolvimento de Novos Produtos
- Especialização nas atividades
- Informação de mercado
- Qualidade do planejamento
- Domínio de trabalho preparatório

\section{Organização}

- Equipe inter-funcional

- Forte Project-leader

- Equipe com responsabilidade pelo projeto

- Forte comunicação inter-funcional

- Ampla autonomia

Cultura Empresarial

- Intrapeneurship

- Abordagem a longo prazo

- Abertura à inovação

- Existência de um product champion

Compromisso de Gestão de Topo

- Alocação de recursos

- Clara definição de objetivos

- Responsabilização pelos resultados

\section{Estratégia}

- Objetivos claros para os novos produtos

- Clara direção para os diversos projetos

- Orientação a longo prazo

Fonte: Ernst (2002). volvimento da exploração das oportunidades surgidas, o que permite uma filtragem seletiva das empresas existentes. As empresas que não conseguirem inovar e que não derem resposta adequada ao mercado, entrarão em disfunção e eventual falência, completando assim o ciclo de destruição criativa (SCHUMPETER, 1943).

A inovação tecnológica tem sido um desafio constante no processo de DNP. O relacionamento inovação/tecnologia ao longo do ciclo de vida do produto foi inicialmente desenvolvido por Abernathy e Utterback (1975) para descrever os vários padrões da inovação ao longo do ciclo de vida da indústria. Este relacionamento defende que as inovações radicais para produtos e processos são mais importantes numa fase inicial do ciclo de vida, enquanto que as inovações incrementais são mais importantes na fase final. A relação entre inovações de produto e de processo é igualmente relevante, sendo as primeiras mais importantes enquanto não se atinge o design dominante, passando a partir deste a ser mais importantes as segundas.

Tushman e Anderson (1986) estudaram o impacto das descontinuidades tecnológicas e os padrões de mudança tecnológica na indústria. Eles demonstraram que a tecnologia evolui de forma incremental, embora algumas mudanças radicais, impossíveis de predizer, a alterem ao longo do tempo. Estas inovações radicais, que aumentam a incerteza ambiental, foram designadas por Anderson et al. (1990) como competence-destroying e competenceenhancing. O seu estudo mostrou que as inovações do tipo competence-destroying eram introduzidas por concorrentes extra-indústria e estavam associadas a uma turbulência ambiental acrescida. As descontinuidades do tipo competence-enhancing eram introduzidas por empresas da indústria e, normalmente, estavam associadas a turbulências ambientais diminutas.

Anderson e Tushman (1990) confirmaram o conceito de Abernathy et al. (1975) sobre o design dominante e acrescentaram que, após o seu aparecimento, as mudanças tecnológicas consistem em melhorias contínuas que podem dar origem a um novo standard: marca o fim de um processo de inovação radical e o começo de um processo de inovação incremental.

Nelson e Winter (1977) propuseram o conceito de trajetória natural, de forma a descrever os vários padrões da inovação. Eles sugeriram que em indústrias onde as mudanças tecnológicas são muito rápidas, as inovações parecem acontecer de um modo inevitável. Eles basearam o seu conceito de trajetórias naturais em três aspectos importantes: a rotina organizacional, as atividades de investigação e o ambiente empresarial. Enquanto que as primeiras estão relacionadas com as 
rotinas internas, que permitem internalizar novos conhecimentos, as segundas estão relacionadas com a evolução/modificação das rotinas atuais, baseando-se para tal nos conhecimentos científicos. O ambiente empresarial está relacionado com as diferentes recompensas, motivações e critérios de sucesso.

\section{O ENVOLVIMENTO DOS FORNECEDORES NO DNP}

As abordagens colaborativas têm recebido uma atenção crescente devido à concorrência global e ao aumento da complexidade tecnológica. No entanto, quando o DNP é abordado colaborativamente, a perspectiva tradicional é posta em causa, dado que a competitividade das várias empresas ao longo da cadeia de valor afeta diferenciadamente todos os seus atores, devido à sua natureza não-linear e ao seu processo iterativo.

Håkansson (1987) e Lamming (1993) deram uma nova vida ao relacionamento inter-empresarial ao demonstrar que este é evolutivo ao longo do tempo, de natureza cumulativa e depende: a) do envolvimento tanto do fornecedor como do cliente; b) da atmosfera que afeta a interação; e c) do ambiente no qual o relacionamento ocorre. De acordo com Lamming (1993), são nove os fatores que afetam o relacionamento, tal como se apresenta na Tabela 3.

O grande problema do relacionamento inter-empresarial é a progressiva integração de alguns fornecedoreschave no negócio do produtor. Esta integração implica um compromisso competitivo e cooperativo entre os parceiros envolvidos (BERTODO, 1991; CLARK, 1989), o que permite o abandono de abordagens antagônicas ao longo da cadeia de valor e o início de abordagens cooperativas, em que os fornecedores dispõem de vantagens proprietárias competitivas que complementam as vantagens competitivas dos seus clientes.

A importância do desenvolvimento colaborativo de novos produtos (DCNP) foi inicialmente explicitada por Womack et al. (1992) e Clark et al. (1991). Eles conseguiram demonstrar que, para além da criação de novos conceitos e da adaptação contínua às necessidades dos clientes, o DCNP permite a melhoria do custo do produto, a melhoria do custo de desenvolvimento do produto, a diminuição do tempo de desenvolvimento, a minimização do tempo de fabricação e a melhoria do desempenho do produto, devido à intervenção dos agentes envolvidos no processo de desenvolvimento.

O envolvimento dos fornecedores desde a fase de concepção dos produtos passou a ser de primordial importância na implementação de novos produtos/sistemas. Clark (1989) foi ao ponto de propor que os fornecedores e os clientes baseassem o seu relacionamento no que designou de reciprocidade: fornecedores e clientes assumindo tarefas não sobrepostas no processo de desenvolvimento de novos produtos, de forma a tirarem proveito das competências nucleares críticas de cada parceiro. Wheelwright e Clark (1995) vão ao ponto de afirmar que a competitividade a longo prazo das empresas industriais depende do desenvolvimento conjunto de competências de design de novos produtos, devido à sua complexidade e à sua natureza não-linear e iterativa.

Uma mudança de atitude relacional é fundamental de forma a (BERTODO, 1991; CLARK, 1989; LAMMING, 1993): a) reduzir o tempo de desenvolvimento de novos produtos; b) gerir atividades sobrepostas de vários parceiros no rápido desenvolvimento de protótipos; c) envolver e comprometer os fornecedores no investimento de ferramentas; d) alcançar níveis superiores de qualidade; e e) tratar os fornecedores como parceiros. $\mathrm{Na}$

Tabela 3: Fatores que afetam o relacionamento fornecedor-cliente.

A natureza da concorrência no mercado fornecedor

A política de abastecimento do cliente

O papel da política da informação e a forma como é gerida por ambos os parceiros

O planejamento conjunto da capacidade produtiva

A logística na cadeia de valor

A atitude de ambos os parceiros perante as mudanças de preços

A política da qualidade e a forma como é gerida

O papel da P\&D na criação conjunta de novos produtos e processos

O nível de pressão no relacionamento

Fonte: Lamming (1993). 
realidade, de acordo com Kamath e Liker (1994), esta mudança de atitude relacional não está ao alcance de todos os produtores nem de todos os fornecedores devido a complexidades tecnológicas, a diferenciais de capacidades de gestão e à necessidade de desempenho global.

O trabalho de Dyer (1996) veio dar uma nova luz ao relacionamento inter-empresarial vertical: ele demonstrou que a qualidade, o tempo de desenvolvimento de novos produtos, os custos de armazenagem e a rentabilidade de ambos os parceiros, o fornecedor e o cliente, eram afetados pela forma como as empresas se relacionavam. O resultado foi notório: os construtores nipônicos de automóveis, bem como os seus fornecedores, estavam bem melhor posicionados nos quatro critérios avaliados do que os construtores americanos e os seus fornecedores, devido ao melhor relacionamento a montante.

Kamath e Liker (1994) abordaram o relacionamento inter-empresarial partindo da perspectiva dos fornecedores, o que representa uma importante inovação na consideração de uma dinâmica evolutiva no relacionamento inter-empresarial. Tal como se apresenta na Tabela 4, Kamath e Liker (1994) apresentam os diferentes papéis dos fornecedores no DCNP ao longo de quatro estágios de desenvolvimento de relacionamentos inter-empresariais tendo em consideração sete aspectos do DCNP.

Claramente, na fase contratual o fornecedor é utilizado como uma mera extensão da capacidade produtiva do cliente, dado que o design é da responsabilidade do cliente e a capacidade tecnológica do fornecedor é baixa. Por sua vez, na fase de envolvimento o fornecedor é envolvido logo na fase de pós-conceito e participa no desenvolvimento colaborativo de subconjuntos simples.

$\mathrm{Na}$ fase de maturidade, embora o fornecedor tenha um amplo envolvimento no DCNP, o cliente mantém uma posição de controle, tirando partido da ampla especialização do fornecedor. Finalmente, na fase de parceria, o fornecedor assume a responsabilidade do design desde a altura do pré-conceito do produto, devido às suas amplas competências tecnológicas e à sua capacidade em produzir subsistemas complexos de valor acrescentado para o cliente.

É notório que os quatro estágios do desenvolvimento inter-empresarial correspondem a fases evolutivas em que a progressão na escada tecnológica por parte do fornecedor é fundamental para evoluir da fase contratual à fase de parceria. De acordo com Kamath e Liker (1994), a dimensão da empresa, as suas competências tecnológicas a nível de investigação e de DNP são fundamentais para desenvolver capacidades relacionais.

Dowlatshahi (1998), de forma a abordar o problema relacional, propõe uma ferramenta conceitual que aborda diferentes funções intra e inter-funcionais. Ele propõe a utilização de uma série de tarefas a nível multifuncional, de forma a avaliar o envolvimento relacional dos fornecedores no design conjunto, nas atividades de manufatura e nas atividades logísticas. Embora não siga uma abordagem evolutiva, Dowlatshahi (1998) recomenda equipes

Tabela 4: Papéis dos fornecedores.

\begin{tabular}{|c|c|c|c|c|}
\hline \multirow{2}{*}{ INDIGADORES DO DGNP } & \multicolumn{4}{|c|}{ Estágios de desenvolvimento dos relacionamentos inter-empresariais } \\
\hline & Contratual & Envolvimento & Maturidade & Parceria \\
\hline 1. Responsabilidade do Design & Cliente & Conjunto & Fornecedor & Fornecedor \\
\hline 2. Complexidade do Produto & $\begin{array}{l}\text { Componentes } \\
\text { Simples }\end{array}$ & $\begin{array}{l}\text { Subconjuntos } \\
\text { Simples }\end{array}$ & $\begin{array}{l}\text { Subconjuntos } \\
\text { Complexa }\end{array}$ & Subsistema \\
\hline 3. Especificações Fornecidas & $\begin{array}{l}\text { Design } \\
\text { Completo }\end{array}$ & $\begin{array}{l}\text { Especificações } \\
\text { Detalhadas }\end{array}$ & $\begin{array}{l}\text { Especificações } \\
\text { Críticas }\end{array}$ & Conceito \\
\hline $\begin{array}{l}\text { 4. Influência do Fornecedor nas } \\
\text { Especificações }\end{array}$ & Nenhuma & Algumas & Negociadas & Colaboração \\
\hline $\begin{array}{l}\text { 5. Estágio em que o Fornecedor } \\
\text { se Envolve }\end{array}$ & Protótipo & Pós-conceito & Conceito & Pré-conceito \\
\hline $\begin{array}{l}\text { 6. Responsabilidade do Teste do } \\
\text { Componente }\end{array}$ & Menor & Moderada & Amplas & Completa \\
\hline $\begin{array}{l}\text { 7. Capacidade Tecnológica do } \\
\text { Fornecedor }\end{array}$ & Baixa & Média & Amplas & Autônomo \\
\hline
\end{tabular}

Fonte: Kamath e Liker (1994) 
inter-disciplinares e interdependentes, de forma a aumentar o grau de envolvimento dos diversos parceiros, o que complementa a abordagem seguida por Kamath e Liker (1994).

\section{UMA RETROSPECTIVA CRÍTICA}

Os trabalhos de Lamming (1993) e Dyer (1996) foram de importância crucial porque permitiram encarar o relacionamento vertical como se de uma única empresa se tratasse. É notório que o relacionamento proposto por Lamming (1993) é um relacionamento cumulativo em que a tecnologia e a inovação só começam a ser consideradas conjuntamente depois de um processo de acumulação operacional bem-sucedido que envolve políticas conjuntas de produção, de qualidade, de informação, de logística e de abastecimento. Nestas circunstâncias, não é de estranhar que, após um longo período de maturação conjunta, ambas as empresas decidam encetar um processo de colaboração a nível tecnológico e de inovação que envolva a criação de novos produtos e partilhas tecnológicas.

Pode-se dizer que o relacionamento proposto por Lamming (1993) acontece porque o design dominante (ABERNATHY et al., 1975) e a trajetória natural da tecnologia (NELSON et al., 1977) já tinham sido atingidos. Nestas circunstâncias, é plausível afirmar que as descontinuidades tecnológicas já tinham sido "controladas", pelo que o alinhamento conjunto entre o fornecedor e o cliente não é mais do que um conjunto de inovações incrementais que deu origem a um modelo de inovação onde ambas as empresas tiram proveito de inovações complementares competence-enhancing, de acordo com Anderson et al. (1990) - que dão origem a benefícios mútuos através da co-especialização.

A tecnologia e a inovação têm uma característica comum: o seu caráter cumulativo e a sua associação na criação de vantagens competitivas para ambas as empresas. Uma crítica pode, não obstante, ser feita: é assumido tacitamente que tanto a tecnologia como a inovação têm origem na empresa e funcionam para o seu interesse. Nestas circunstâncias, tanto o produtor como o fornecedor podem ter interesses antagônicos.

Com o aparecimento das estratégias colaborativas verticais, e sobretudo devido ao interesse conjunto de ambos os parceiros na cadeia de valor, a inovação e a tecnologia começaram a ser encaradas tendo em consideração o interesse conjunto, pelo que é necessário abordar as teorias acima apresentadas tendo em conta algumas particularidades, nomeadamente a partir do "produto" em causa.

Em nível de envolvimento no processo de DNP, os fornecedores podem ser divididos em quatro categorias, de acordo com o tipo de produtos que fornecem, a saber: as Supplier-proprietary parts, as Black-box parts, as Greybox parts e as Detail-controlled parts (LAMMING, 1993; CLARK e FUJIMOTO, 1991):

- As Supplier-proprietary parts são componentes cujo desenvolvimento é responsabilidade do fornecedor. Dado que se tratam de componentes genéricos, a sua influência a jusante é fraca;

- As Black-box parts são componentes cujos requerimentos a nível funcional e de desempenho são especificados pelos clientes, mas cujos detalhes técnicos e de engenharia são executados pelos fornecedores. Isto permite ao produtor utilizar a base de conhecimentos e de engenharia do fornecedor enquanto mantém o controle tecnológico do produto final;

- As Grey-box parts são componentes semelhantes aos black-box mas com a particularidade de serem também os produtores a controlar o funcionamento interno destes componentes; e

- As Detail-controlled parts, que são componentes cujos requerimentos técnicos e design são inteiramente executados pelos produtores. Neste caso, o envolvimento dos fornecedores é muito passivo, dado que todo o processo de decisão é responsabilidade do produtor.

\section{envolvimento do fornecedor no processo de desenvolvimento de novos produtos permite ao cliente complementar as suas vantagens competitivas com as vantagens
competitivas dos seus fornecedores.}

De referir que o fornecedor não está envolvido no desenvolvimento colaborativo de novos produtos nem nas supplier-proprietary parts nem nas detail-controlled parts. No primeiro caso, isto deve-se ao fato de se tratar de componentes genéricos, pelo que o "relacionamento" é quase nulo. No segundo caso o envolvimento é passivo, dado que todo o processo de decisão é tomado pelo produtor.

A cada tipo de produto correspondem interesses diferenciados para cada um dos participantes, como representado na Tabela 5. Nota-se que existem dois extremos 
diferenciados: os produtos do tipo Supplier-proprietary e os produtos do tipo Detail-controlled. Enquanto que estes últimos se encontram numa fase inicial do seu desenvolvimento, ou poderão ser considerados como produtos nucleares à empresa produtora, os supplierproprietary parts estão numa fase de maturidade. Por sua vez, os produtos do tipo Black-box e Grey-box estão num estágio intermédio entre os dois. parts e os subsistemas, com os outros três tipos de produtos mencionados na Tabela 5. Assim, em termos de produtos e de subsistemas, há duas situações que são bem diferenciadas no relacionamento inter-empresarial a nível de inovação tecnológica e que estão relacionadas com a co-especialização de ambos os parceiros, e que levam a relacionamentos diferentes.

\section{A relacionamento cooperativo com co-especialização ambos os parceiros} têm vantagens, dado que se beneficiam de inovações do tipo competence-enhancing.

\section{Relacionamento cooperativo com co- especialização}

O relacionamento cooperativo com co-especialização diz respeito ao relacionamento inter-empresarial baseado em componentes do tipo Supplierproprietary parts e em subsistemas do tipo Black-box e Grey-box. Como mencionado por Moreira (2002), um exemplo deste relacionamento são os fabricantes

Em termos de relacionamento existem duas situações diferentes que têm a ver com a co-especialização dos parceiros. Nos produtos do tipo Detail-controlled o produtor não efetuou nenhum relacionamento cooperativo a montante por uma razão muito simples: o design dominante do produto (ABERNATHY et al., 1975) e a trajetória tecnológica (NELSON et al., 1977) ainda não estão completamente definidos, pelo que o cliente mantém toda a responsabilidade na sua definição. Nos outros três tipos de produtos mencionados na Tabela 5 a situação é inversa: tanto o design dominante como a trajetória tecnológica já foram definidos, pelo que o produtor efetua um relacionamento conjunto a montante, de forma a obter benefícios das inovações complementares propostas pelo fornecedor.

Em nível de complexidade de produtos, há duas situações diferentes: os componentes e os subsistemas. Como o nome indica, os componentes, embora produtos acabados para o fornecedor, destinam-se a ser incorporados numa fase subseqüente da cadeia de valor. Por sua vez, um subsistema é um produto cuja complexidade tecnológica é bem superior à dos componentes e poderá ser gerido tanto pelo produtor como pelo fornecedor, dependendo do produto em causa. Nestas circunstâncias, os componentes identificam-se com os supplier-proprietary de sistemas de regulação de altura dos cintos de segurança do setor automóvel. A sua tecnologia está orientada para a engenharia-de-produto e a sua base tecnológica interna é fundamental para os grandes construtores do setor automobilístico, dado que possuem competências próprias em injeção de plásticos, moldes e ferramentas metálicas, pelo que servem de elo de ligação a montante com os fabricantes de ferramentas metálicas. É a coespecialização que torna estas empresas fulcrais para os seus clientes.

Neste relacionamento, os fornecedores e os clientes têm vantagens a diversos níveis, dado que procuram tirar proveito de inovações do tipo competence-enhancing de que ambos se beneficiam. É notório que mesmo que haja uma ruptura tecnológica e o design dominante não tenha sido atingido, ambos os parceiros poderão tirar proveito das posições privilegiadas na parceria vertical, de forma a ter acesso às novas tecnologias e aos novos desenvolvimentos: se esta tiver origem a montante, o produtor "forçará" o fornecedor a internalizá-la, de forma a não pôr em causa a sua relação privilegiada; igualmente, se a ruptura tecnológica ocorrer a jusante, o fornecedor procurará investir na nova tecnologia, de forma a não perder o posicionamento ganho na parceria.

No nível de redução do risco, tanto o fornecedor como

Tabela 5: Tipos de produtos e interesses no relacionamento fornecedor-cliente.

\begin{tabular}{|l|l|l|l|}
\hline \multicolumn{1}{|c|}{ TIPO DE PRODUTOS } & TECNOLOGIA E INOVAÇÃO & COMPETÊNCIAS BASE & CO-ESPECIALIZAÇÃO \\
\hline Supplier-proprietary parts & Fornecedor & Fornecedor & (Sim) \\
\hline Black-box parts & Ambos (Fornecedor) & Ambos (Fornecedor) & Sim \\
\hline Grey-box parts & Ambos (Produtor) & Ambos (Produtor) & Sim \\
\hline Detail-controlled parts & Produtor & Produtor & Não \\
\hline
\end{tabular}


o cliente têm vantagens num relacionamento cooperativo. O primeiro, mesmo aceitando um risco maior, vê o seu negócio melhor assegurado por estar relacionado com a fase de criação de novos conceitos com aquele que é o cliente e potencial utilizador do produto. O segundo também vê diminuir o risco, dado que envolve o fornecedor no desenvolvimento de uma nova tecnologia e se baseia nos seus conhecimentos para desenvolver os novos conceitos.

Uma conseqüência desta redução do risco é que a mudança técnica é facilitada, dada a complementaridade tecnológica assegurada por cada um dos parceiros, o que faz com que a inovação tecnológica seja operacionalizada entre ambos os parceiros, fazendo com que o processo de difusão tecnológica seja acelerado.

No nível de integração vertical, a mudança partilhada permite aos parceiros um benefício amplo. O produtor pode tirar proveito da "efetiva" integração vertical, tirando partido de uma subcontratação baseada: a) na complementaridade inter-empresarial; e b) nas tecnologias competence-enhancing que o parceiro a montante, entretanto, efetuou. Por sua vez, o fornecedor pode tirar proveito do seu posicionamento tecnológico (co-especialização) e acompanhar o negócio do produtor sem correr o risco de uma "real" integração.

A pseudo-integração vertical dá origem a economias de co-especialização, que acabam por ser economias de escala baseadas em competências nucleares específicas de cada parceiro e em que a grande vantagem está em tirar proveito de uma idéia conjunta em benefício mútuo. Assim, a partilha de experiências e investimento acaba por funcionar como alavanca de inovações conjuntas, por um lado, e como redutor de riscos tecnológicos, por outro. No fundo, ambos os parceiros tiram proveito da sua co-especialização sem perder a sua soberania.

A aprendizagem, sobretudo a nível organizacional, tem sido exposta como um dos drivers do sucesso empresarial japonês:

Kanban, JIT, Poka-Joke, Sistema de Produção Toyota, Gestão pela Qualidade Total, Kaizen, etc. No nível de aprendizagem, o grande desafio da mudança partilhada está não só em implementar algumas destas filosofias operacionais, mas também em fazer com que as empresas as possam implementar a nível tecnológico, tirando proveito da sua coespecialização. Assim, as empresas terão de ultrapassar as suas fronteiras empresariais e funcionais, de forma a poderem tirar partido das suas competências.

Um novo desafio se coloca em nível organizacional sempre que as empresas pretenderem efetuar uma mu- dança partilhada na cadeia de valor: a complementaridade tecnológica, a co-especialização e a aprendizagem só ocorrerão se ambos os parceiros se organizarem/relacionarem em termos de competências. Para tal, terão de abandonar o clássico relacionamento funcional, baseado no relacionamento hierárquico produtor (sênior)-fornecedor (júnior), e encetar práticas conjuntas de relacionamento tecnológico com objetivos partilhados.

Relacionamento cooperativo sem co-especialização

$\mathrm{O}$ relacionamento cooperativo sem co-especialização diz respeito ao relacionamento fornecedor-cliente baseado em subsistemas do tipo Detail-controlled parts. Neste relacionamento o produtor está numa situação de vantagem face ao fornecedor, dado que tanto a tecnologia como a inovação têm origem no produtor. Não é estranho que, nesta situação, não haja co-especialização.

Um exemplo deste tipo de relacionamento é dado pelos produtores dos assentos dos carros/aviões. Quando alguns produtores conseguem fabricar estruturas metálicas baseadas em compósitos poliméricos reforçados com fibras de carbono que substituem as estruturas metálicas em alumínio, acabam por pôr em causa todo o relacionamento a montante com os fornecedores das tecnologias mais maduras e dos materiais mais antigos. Assim, o relacionamento com os fornecedores de aço e com as empresas de corte, dobragem e estampagem pode ser posto em causa se estes não conseguirem desenvolver tecnologias de moldação por compressão.

\section{No relacionamento cooperativo sem co-especialização o produtor está numa situação de vantagem face ao fornecedor: tanto a tecnologia como a inovação têm origem no produtor.}

Em nível de risco, o fornecedor procurará aumentar a sua participação na criação de novos conceitos, o que implicará um maior empenho e investimento em P\&D. O produtor, por sua vez, só envolverá o fornecedor se este conseguir aportar inovações do tipo competenceenhancing. A curto prazo, o risco é elevado para o fornecedor, só havendo perspectivas de diminuição do risco se a trajetória tecnológica estiver definida e a complementaridade tecnológica entre ambos os parceiros for efetiva.

As economias de co-especialização só se farão sentir se ambos os parceiros investirem em partilha de experiên- 
cias com vista a incorporar competências-base complementares. Apenas nesta circunstância é que o investimento conjunto reduzirá o risco tecnológico para ambos os parceiros.

Neste relacionamento sem co-especialização a posição do fornecedor é bastante desvantajosa, dado que poderá haver empresas externas ao relacionamento que pelas suas competências tecnológicas procurem desalojar o fornecedor da sua posição privilegiada no relacionamento e assumir com o produtor um novo relacionamento.

\section{CONCLUSÃO}

A vantagem competitiva das empresas está intrinsecamente ligada à inovação e ao domínio das aplicações tecnológicas. Estas, por sua vez, têm feito sentir a sua influência no processo de desenvolvimento de novos produtos e estão presentes ao longo de toda a cadeia de valor.

O relacionamento fornecedor-cliente tem, igualmente, uma importância fulcral no desenvolvimento colaborativo de novos produtos e na competitividade empresarial. Classicamente, ele foi considerado como antagônico e só a partir dos anos 80 é que houve mudanças estratégicas importantes nas empresas, que lhe moldaram um novo formato. Lamming (1993), com um trabalho meritório, deu grande ênfase ao trabalho cooperativo entre empresas de níveis diferentes na cadeia de valor e caracterizou os principais fatores a ter em consideração para que o relacionamento fornecedor-cliente fosse bem-sucedido.

$\mathrm{O}$ artigo procura questionar a teoria sobre a competição/cooperação tirando proveito dos postulados de Lamming (1993), das teorias da inovação e da tecnologia, e da mudança partilhada na cadeia de valor. Assim, o artigo pôs em evidência a particularidade da relação fornecedor-cliente em duas situações completamente diferentes, como são a co-especialização dos parceiros e o tipo de produto transacionado entre ambos.

Nos relacionamentos cooperativos com co-especialização, tanto os fornecedores como os clientes fazem face às mudanças partilhadas, tirando partido das suas competências próprias complementares, o que permite a ambos os parceiros beneficiar-se de um baixo nível de risco, de economias de co-especialização e de uma aprendizagem organizacional induzida.

Por sua vez, nos envolvimentos colaborativos sem coespecialização, o fornecedor se encontra numa situação desvantajosa face ao produtor sempre que este procura impor inovações radicais. Nestas circunstâncias, sempre que a trajetória tecnológica não esteja definida e o design dominante não tenha sido atingido, é plausível afirmar que os produtores procurarão tirar partido das suas inovações radicais internalizando as competências nucleares e as novas tecnologias incorporadas, podendo, assim, pôr em causa a posição do fornecedor na parceria.

Embora não seja possível questionar as teorias dos relacionamentos cooperativos, a grande vantagem do artigo está na contribuição para a discussão dessas teorias, sobretudo quando há inovações que impõem mudanças na trajetória tecnológica e no design dominante. Assim, é plausível afirmar que é recomendável aprofundar estes envolvimentos colaborativos verticais especialmente quando do DCNP, em que os parceiros apresentam relacionamentos cooperativos com e sem co-especialização.

Igualmente importante para a discussão da teoria da competição/cooperação é o aprofundamento da pesquisa englobando parcerias no desenvolvimento de novos produtos que envolvam componentes, subsistemas e produtos finais, com e sem co-especialização, de forma a poder aprofundar o conhecimento dos fenômenos em estudo relacionados com o DCNP e com o relacionamento interempresarial. 
ABERNATHY, D.A.; UTTERBACK, J.M. A Dynamic Model of Process and Product Innovation. Omega, v. 3, n 6, 1975 .

ANDERSON, P.; TUSHMAN, M.L. Technological Discontinuities and Dominant Designs: A Cyclical Model of Technological Change. Administrative Science Quarterly. v. 35 p. $604-633,1990$

BERTODO, R. The Role of Suppliers in Implementing a Strategic Vision. Long Range Planning, v. 22, p. 40-48, 1991.

CLARK, K.B. Project Scope and Project Performance: The Effects of Parts Strategy and Supplier Involvement on Project Development. Management Science, v. 35, n. 10 p. 1247-1263, 1989.

CLARK, K.B.; FUJIMOTO, T. Product Development Performance: Strategy, Development and Performance in the World Auto Industry. Boston, MA: Harvard Business School Press, 1991.

DESCHAMPS, J.P.; NAYAK, P.R. Product Juggernaut. Boston, MA: Harvard Business School Press, 1995.
DYER, J. H. Specialized Supplier Networks as a Source of Competitive Advantage: Evidence From the Auto Industry. Strategic Management Journal. v. 15, p.271291, 1996

DOWLATSHAHI, S. Implementing Early Supplier Involvement: A Conceptual Framework. International Journal of Operations and Production Management. v. 18, n. 2, p. 143167, 1998.

ERNST, H. Success Factors of New Product Development: A Review of the Empirical Literature. International Journal of Management Reviews, v. 4, n. 1, p. 1-40, 2002.

GRIFFIN, A. Updating Trends and Benchmarking Best Practices. Journal of Product Innovation Management.v. 14, n. 6, p. 427-458, 1997.

HÅKANSSON, H. Industrial Technological Development. A Network Approach. London: Routledge, 1987.

KAMATH, R.; LIKER, J. A Second Look at the Japanese Product Development. Harvard Business Review, p. 157-170, Nov/Dec, 1994.

LAMMING, R. Beyond Partnership: Strategies for Innovation and Lean Supply. London: Prentice Hall, 1993.
MOREIRA, A. C. O Desafio da Integração do Design na Cadeia de Valor. Análise de Case Studies na Indústria Portuguesa. In: II JORNADAS POLITÉCNICAS DE ENGENHARIA, Instituto Politécnico de Setúbal, Setúbal, 2002.

NELSON, R.R.; WINTER, S. In Search of a Useful Theory of Innovation. Research Policy. v. 6, 1977.

ORTEGA, P.M. La Dimensión Estratégica de la Tecnología. Barcelona: Ariel Económica, 1991.

PAVITT, K. Technology Transfer among the Industrially Advanced Countries: An Overview. In: ROSENBERG, N.; FRISCHTAK, C. (Org.). International Technology Transfer: Concepts, Measures and Comparisons. New York: Praeger, 1985

PORTER, M.E. Competitive Advantage. New York: The Free Press, 1985.

RIBAULT, J.M.; MARTINET, B.; LEBIDOIS, D. A Gestão das Tecnologias. Lisboa: Publicações Dom Quixote, 1995.
ROTHWELL, R. Industrial Innovation: Success, Strategy, Trends' Integration and Networking: The Fifth Generation Innovation Process. In: DODGSON, M. ROTHWELL, R (Org.). The Handbook of Industrial Innovation. Cheltenham: Edward Elgard, 1994.

SCHUMPETER, J. Capitalism, Socialism and Democracy. New York: Harper and Row, 1943.

TUSHMAN, M. L.; ANDERSON, P. Technological Discontinuities and Organizational Environments. Administrative Science Quarterly. v. 31 , p. $439-456,1986$

URBAN, G.L.; HAUSER, J.R. Design and Marketing of New Products. New Jersey: Prentice Hall, 1993.

WHEELWRIGHT, S.C.; CLARK, K.B. Creating Project Plans to Focus Project Development. In: CLARK, K.B.; WHEELWRIGHT, S.C. (Org.) The Product Development Challenge: Competing through Speed, Quality and Creativity. Boston, MA: Harvard Business School Press, 1995.

WOMACK, J.; JONES, D.; ROOS, D. A Máquina que Mudou o Mundo. Rio de Janeiro: Campus, 1992.

- Sobre os autores

\section{António Carrizo Moreira}

Professor Auxiliar do DEGEI, Universidade de Aveiro

DEGEI - Departamento de Economia, Gestão e Engenharia Industrial

Campus Universitário de Santiago

3810-193 Aveiro

PORTUGAL

Tel.: (+351) 234370361

Fax: (+351) 234370215

E-mail: amoreira@egi.ua.pt 